\title{
Seleção de Genótipos de Cana-de-Açúcar para Acúmulo de Protoporfirina IX COM Uso de HeRbICIDAs INIBIDORES DA PROTOX ${ }^{1}$
}

\author{
Selection of Sugarcane Genotypes for Protoporphyrin IX Accumulation using Protox-Inhibiting \\ Herbicides
}

BARBERIS, L.R.M. ${ }^{2}$, TRINDADE, M.L.B. ${ }^{3}$ e VELINI, E.D. ${ }^{4}$

\begin{abstract}
RESUMO - O objetivo do presente trabalho foi selecionar genótipos de cana-de-açúcar por meio de inibidores da PROTOX e antioxidantes para indução do acúmulo de protoporfirina IX (PROTO IX) e/ou de seus precursores em plantas. Esses compostos podem ser utilizados como agentes sensibilizantes em terapia fotodinâmica (TFD), os quais possibilitam uma fonte de baixo custo para o tratamento de neoplasias e carcinomas. O experimento foi montado em câmara climatizada, com aplicação de nove tratamentos (1. oxyfluorfen + glutamato monossódico + vitaminas C e E; 2 . oxyfluorfen + glutamato monossódico + vitaminas $\mathrm{C}$ e E + ácido levulênico; 3. oxyfluorfen; 4. carfentrazone + glutamato monossódico + vitaminas $\mathrm{C}$ e $\mathrm{E}$; 5. carfentrazone + glutamato monossódico + vitaminas $\mathrm{C}$ e E + ácido levulênico; 6. carfentrazone; 7. testemunha + vitaminas $\mathrm{C}$ e E; 8. testemunha + vitaminas $\mathrm{C}$ e $\mathrm{E}+$ ácido levulênico; e 9. testemunha) em oito genótipos de cana-de-açúcar (PO933499, RB806043, RB470355, PO830698, SP701143, PO901387, PO894414 e SP903414), dispostos em esquema fatorial $9 \times 8$, com quatro repetições. As repetições constituiram-se de folhas $(20 \mathrm{~cm})$ destacadas de cada genótipo, sendo estas pulverizadas com os tratamentos mencionados, em simulador estacionário. Foram realizadas avaliações visuais de controle aos 2 DAA (dias após aplicação) e, no fim do estudo, determinações analiticas via extração da biomassa fresca, verificando os teores de protoporfirina IX por cromatografia liquida de alta eficiência. Os resultados mostraram que em curto prazo foram detectados aumentos significativos nas concentrações de PROTO IX para os genótipos RB470355 e SP903414 submetidos ao tratamento 2 e para o genótipo SP701143 submetido ao tratamento 8, indicando que eles podem ser utilizados como fontes acumuladoras de protoporfirina IX.
\end{abstract}

Palavras-chave: glutamato, protoporfirina IX, cana-de-açúcar

\begin{abstract}
The objective of this study was to select sugarcane genotypes through PROTOX inhibitors and antioxidants to induce the accumulation of protoporphyrin IX (PROTO IX), or its precursors in plants. Such compounds can be used as sensitizing agents in photodynamic therapy $(P D T)$, being considered a low cost source for the treatment of malignancies. The experiment was set up on a temperature-controlled chamber, with 9 treatments being applied: (1. oxyfluorfen + monosodium glutamate + vitamin C and E; 2. oxyfluorfen + monosodium glutamate + vitamin C and E + levulenic acid; 3. oxyfluorfen; 4. carfentrazone + monosodium glutamate + vitamin Cand E; 5. carfentrazone + monosodium glutamate + vitamin $C$ and $E+$ levulenic acid; 6. carfentrazone; 7. control + vitamin $C$ and E; 8. control + vitamin $C$ and $E+$ levulenic acid; 9. control without spraying in 8 sugarcane genotypes (PO933499, RB806043, RB470355, PO830698, SP701143, PO901387, PO894414 and 8.SP903414); arranged in a factorial $9 \times 8$, with 4 repetitions. The repetitions were constituted by specific leaves $(20 \mathrm{~cm})$ from each genotype, which were sprayed with the appropriate treatments in a stationary simulator. Visual evaluations of the control were carried out at 2 DAA (Days After
\end{abstract}

Recebido para publicação em 31.7.2008 e na forma revisada em 13.11.2009.

2 Engo-Agr ${ }^{0}$, M.Sc., Nupam/FCA-Unesp, Botucatu-SP, Fazenda Experimental Lageado, Caixa Postal 237, 18603-970 Botucatu-SP, <barberis@fca.unesp.br>; ${ }^{3}$ Enga-Agra , Dra., Nupam/FCA-Unesp, Botucatu-SP, <mlbtrindade@uol.com.br>, Fazenda Experimental Lageado, Caixa Postal 237, 18603-970, Botucatu-SP, ${ }^{4}$ Professor, Dr., Dep. de Agricultura FCA/Unesp - Botucatu-SP, Fazenda Experimental Lageado, Caixa Postal 237, 18603-970, Botucatu-SP, <velini@fca.unesp.br>.

Planta Daninha, Viçosa-MG, v. 27, n. 4, p. 809-814, 2009 
Application), and at the end of the study, analytical determinations were conducted via fresh biomass extraction to verify the protoporphyrin IX contents by high performance liquid chromatography. The results showed that significant short-term increases were observed in the PROTO IX concentrations for the genotypes RB470355, SP903414 submitted to treatment 2 and for genotype SP701143 submitted to treatment 8 , indicating that they can be used as accumulating sources of protoporphyrin IX.

Keywords: glutamate, protoporphyrin IX, sugarcane

\section{INTRODUÇÃO}

A sintese de porfirinas é fundamental para a produção de clorofilas em plantas e heme em plantas e animais. As principais diferenças referem-se à alimentação da rota, feita a partir do glutamato em plantas (Nelson et al., 2000) e a partir de glicina e Succinil CoA em humanos (Xiao et al., 1998). A partir do ácido 5-aminolevulênico, as enzimas envolvidas são praticamente as mesmas em todas as transformações necessárias para a produção dos tetrapirróis.

A produção e acúmulo de porfirinas em plantas tem sido bastante estudada, em razão de esses compostos serem precursores das clorofilas e do heme. Adicionalmente, a enzima protoporfirinogênio IX oxidase (PPO ou PROTOX) constitui-se no sítio da ação dos herbicidas difeniléteres (oxyfluorfen, lactofen, fomesafen), oxadiazolinas (oxadiazon e oxadiargil) e ariltriazolinonas (sulfentrazone e carfentrazone). Esse mecanismo de ação dos herbicidas e os compostos que nele atuam são apresentados em detalhes por alguns autores, como Dodge (1992) e Hess (1993). As principais informações são apresentadas a seguir; a inibição da síntese da protoporfirina IX gera um intrigante acúmulo desse pigmento nas plantas tratadas com os herbicidas desse grupo. Em plantas, a protoporfirina IX também apresenta grande reatividade, produzindo, na presença de luz, oxigênio singleto. Ela é produzida nos cloroplastos, pela ação da PROTOX, que tem o protoporfirinogênio IX como substrato. Como a regulação da rota depende prioritariamente da concentração de protoporfirina IX e seus derivados no interior dos cloroplastos, a paralisação da atividade dessa enzima gera grande acúmulo de protoporfirinogênio IX, que extravasa para o citosol. Neste, o protoporfirinogênio IX é convertido, de modo não enzimático, em protoporfirina IX, que é acumulada em grandes concentrações.

A ação e codificação da PROTOX, que está presente e atua nos cloroplastos (produzindo clorofila) e mitocôndrias (produzindo heme), é inteiramente codificada no núcleo (Watanabe et al., 2001). Esses autores também estudaram e demonstraram a existência da translocação intracelular do protoporfirinogênio e da protoporfirina IX. Os resultados indicam que o excesso desses compostos nos cloroplastos e citosol, em decorrência da ação subletal de herbicidas (aplicados em pequenas doses), pode ser utilizado nas mitocôndrias para a produção de grupos heme (Watanabe et al., 2001).

As porfirinas e seus precursores têm sido amplamente usados como agentes fotossensibilizantes na terapia fotodinâmica, cuja denominação foi utilizada pela primeira vez por von Tappeiner em 1904 para descrever a fotossensibilização com consumo de oxigênio que ocorre em tecidos vivos. A TFD vem sendo empregada no tratamento de lesões neoplásicas não melanocíticas, queratinocíticas superficiais, com carcinomas epidermoides, ceratoses, actínicas, carcinomas basocelulares e doenças de Bowen. Já foi utilizada experimentalmente em micose fungoide, sarcoma de Kaposi e ceratoacantomas (Bakos et al., 2003).

Em atividades experimentais, os compostos anticancerígenos fototerapêticos mais usados são o ácido 5-aminolevulênico ou seus ésteres, que podem ser aplicados de forma tópica (compondo cremes ou por instilação intraperitonial) ou sistêmica (por administração oral ou intravenosa.) Nas aplicações sistêmicas, administrações orais e intravenosas induzem a comportamentos farmacocinéticos 
similares do composto (Dalton et al., 2002), indicando que o ácido 5-ALA poderia estar presente como componente de alimentos e com capacidade de induzir a acumulação de PROTO IX.

A Terapia Fotodinâmica (TFD) baseia-se na administração tópica ou sistêmica de um corante não tóxico sensível à luz, seguida da irradiação em baixas doses com luz visivel de comprimento de onda adequado (Gad et al., 2004). Na presença de oxigênio encontrado nas células, o fotossensibilizador (FS) ativado pode reagir com moléculas na sua vizinhança por transferência de elétrons ou hidrogênio, levando à produção de radicais livres (reação do tipo I), ou por transferência de energia ao oxigênio (reação do tipo II), levando à produção de oxigênio singleto. Ambos os caminhos podem levar à morte celular e à destruição do tecido doente (Lambrechts et al., 2005; Demidova et al., 2005) .

Outras vantagens da TFD são: ser efetiva teoricamente em todos os tipos de câncer e dispensar a especificidade dos agentes quimioterapêuticos e a radiação ionizante. Comparada com outras terapias citotóxicas, a TFD tem a vantagem de dupla seletividade: não apenas o FS pode ser direcionado para as células ou tecido doente, mas também a luz pode ser precisamente focalizada no local da lesão (Demidova et al., 2004; Hamblin \& Hasan, 2004).

A maior limitação do uso da TFD é a baixa disponibilidade e / ou alto custo dos fotossensibilizadores. Os fotossensibilizadores mais utilizados em TFD do câncer são os derivados de hematoporfirina, e o Photofrim ${ }^{\circledR}$ (Canadá) é o mais conhecido, tendo sido autorizado para uso clínico em 1998 nos Estados Unidos, seguido por Canadá, Holanda, França, Alemanha e Japão (Capella \& Capella, 2003). Os fotossensibilizadores correspondentes produzidos na Alemanha e Rússia são, respectivamente, Photosan ${ }^{\mathbb{}}$ e Photogem ${ }^{\circledR}$ (Menezes et al., 2005).

Este trabalho teve como principal objetivo selecionar genótipos de cana-de-açúcar como unidades de produção ou como fontes de dois importantes agentes fotossensibilizantes, que são o ácido 5-aminolevulênico e a protoporfirina IX.

\section{MATERIAL E MÉTODOS}

O experimento foi conduzido no Núcleo de Pesquisas Avançadas em Matologia - NUPAM da Faculdade de Ciências Agronômicas da UNESP, campus de Botucatu-SP. A aplicação dos tratamentos foi feita em pulverizador experimental regulado para um consumo de calda de $1.000 \mathrm{~L} \mathrm{ha}^{-1}$, em pedaços de $20 \mathrm{~cm}$ de folhas, dispostas horizontalmente em bandejas plásticas. Após esta etapa, as folhas foram inseridas em copos plásticos com algodão umedecido no fundo e, em seguida, alocadas em câmara climatizada a $25^{\circ} \mathrm{C}$, com $70 \%$ de umidade relativa e fotoperíodo de 14 horas de luz durante 15 dias.

Foram adotados nove tratamentos: 1 . oxyfluorfen $\left(6 \mathrm{~mL}\right.$ p.c. $\left.\mathrm{L}^{-1}\right)+$ glutamato monossódico $\left(10 \mathrm{~g} \mathrm{~L}^{-1}\right)+$ vitaminas $\mathrm{C}$ e $\mathrm{E}\left(25 \mathrm{~g} \mathrm{~L}^{-1} \mathrm{e}\right.$ $\left.2,5 \mathrm{~mL} \mathrm{~L}^{-1}\right) ; 2$. oxyfluorfen $\left(6 \mathrm{~mL}\right.$ p.c. $\left.\mathrm{L}^{-1}\right)+$ glutamato monossódico $\left(10 \mathrm{~g} \mathrm{~L}^{-1}\right)+$ vitaminas C e E $\left(25 \mathrm{~g} \mathrm{~L}^{-1}\right.$ e $\left.2,5 \mathrm{~mL} \mathrm{~L}^{-1}\right)+$ ácido levulênico $(0,1 \%$ imersão das folhas uma hora antes da pulverização); 3. oxyfluorfen (6 mL p.c. $\left.\mathrm{L}^{-1}\right) ; 4$. carfentrazone $\left(0,250 \mathrm{~mL}\right.$ p.c. $\left.\mathrm{L}^{-1}\right)+$ glutamato monossódico $\left(10 \mathrm{~g} \mathrm{~L}^{-1}\right)+$ vitaminas $\mathrm{C}$ e $\mathrm{E}$ (25 $\mathrm{g} \mathrm{L}^{-1}$ e $\left.2,5 \mathrm{~mL} \mathrm{~L}^{-1}\right)$; 5. carfentrazone $\left(0,250 \mathrm{~mL}\right.$ p.c. $\left.\mathrm{L}^{-1}\right)+$ glutamato monossódico $\left(10 \mathrm{~g} \mathrm{~L}^{-1}\right)+$ vitaminas C e E $\left(25 \mathrm{~g} \mathrm{~L}^{-1}\right.$ e $\left.2,5 \mathrm{~mL} \mathrm{~L}^{-1}\right)+$ ácido levulênico $(0,1 \%$ imersão das folhas uma hora antes da pulverização); 6. carfentrazone $\left(0,250 \mathrm{~mL}\right.$ p.c. $\left.\mathrm{L}^{-1}\right) ; 7$. testemunha + vitaminas C e E $\left(25 \mathrm{~g} \mathrm{~L}^{-1}\right.$ e $\left.2,5 \mathrm{~mL} \mathrm{~L}^{-1}\right)$; 8. testemunha + vitaminas $\mathrm{C}$ e E $\left(25 \mathrm{~g} \mathrm{~L}^{-1}\right.$ e $\left.2,5 \mathrm{~mL} \mathrm{~L}^{-1}\right)+$ ácido levulênico $(0,1 \%$ imersão das folhas uma hora antes da pulverização); 9. testemunha, os quais foram aplicados em oito diferentes genótipos: PO933499, RB806043, RB470355, PO830698, SP701143, PO901387, PO894414 e SP903414. Portanto, o delineamento experimental adotado foi inteiramente casualizado em esquema fatorial $9 \times 8$, com quatro repetições (cada repetição constituiu-se de um pedaço de $20 \mathrm{~cm}$ de folha de cana). Os sintomas de acúmulo de porfirinas foram avaliados aos 2 DAA dos tratamentos. A avaliação consistiu na determinação da porcentagem da superfície com a cor característica da porfirina (marrom-avermelhada) através de notas visuais de controle, baseadas em uma escala percentual, em que 0 representa nenhum sintoma e 100 , sintomas por toda a superficie da folha (Tabela 2).

Planta Daninha, Viçosa-MG, v. 27, n. 4, p. 809-814, 2009 
Após a avaliação, as folhas foram coletadas e acondicionadas em freezer a $-20{ }^{\circ} \mathrm{C}$. A parte laboratorial envolveu duas etapas: extração e análise do material. Para a extração, utilizouse o método segundo Pornprom et al. (1994) e Sherman et al. (1991), cuja biomassa fresca das plantas é triturada em grau de porcelana com auxílio de nitrogênio líquido ou de areia purificada. Após a trituração das folhas, a extração foi feita com $8 \mathrm{~mL}$ de metanol e hidróxido de amônio em 0,2 grama do material triturado em ambiente protegido de luz. Para isso, tubos "falcon" foram envolvidos com papel-alumínio antes de passarem no ultrassom, centrifugados a $6.000 \mathrm{rpm}$ por 15 minutos e, então, filtrados em filtro tipo membrana GV Millex $0,22 \mu \mathrm{m}$. As análises foram realizadas em CLAE-EM (cromatógrafo líquido de alta eficiência acoplado a um espectrômetro de massa tipo quadropolo), marca Shimadzu, modelo 2010EV, que apresenta resposta uniforme a grupos de compostos com características similares, mantendo uma relação aproximadamente constante entre a intensidade de sinal (área do pico cromatográfico) e a concentração dos diferentes compostos, expressas em unidades molares.

Para as análises, as condições do CLAE estabelecidas foram os seguintes gradientes dos solventes (metanol, água e metanol/ $0,1 \mathrm{~mol} \mathrm{~L}^{-1}$ de $\mathrm{NH}_{4} \mathrm{OH}$ e acetonitrila $9 / 1 \mathrm{v} / \mathrm{v}$ ) na fase móvel. A coluna empregada foi uma pré-coluna de $\mathrm{C}_{18}$ (Carbono 18) de marca Shimadzu, com volume de injeção de $5 \mu \mathrm{L}$. O tempo total de corrida foi de 15 minutos, e o tempo de retenção da proporfirina IX, de 7,1 minutos. Foram estabelecidos seis pontos para a curva de calibração, sendo empregada a quantificação em diferentes concentrações do padrão de protoporfirina IX. Os resultados foram submetidos à análise de variância pelo teste $\mathrm{F}$, e a comparação de médias foi feita pelo teste de Tukey a $5 \%$ de probabilidade.

\section{RESULTADOS E DISCUSSÃO}

Por meio dos resultados obtidos com o método analítico, observaram-se maiores acúmulos em $\mu \mathrm{g} \mathrm{g}^{-1}$ de protoporfirna IX nos genótipos SP903414 e RB470355 submetidos ao tratamento 2 e SP701143 submetido ao tratamento 8, encontrando-se, respectivamente, 19,75, 21,25 e 15,25 $\mu \mathrm{g} \mathrm{g}^{-1}$, diferindo significativamente da testemunha dos genótipos correspondentes, conforme Tabela 1 . As maiores concentrações foram observadas com o uso do inibidor da PROTOX, juntamente com os precursores e antioxidantes, demonstrando a inibição da enzima protoporfirinogênio oxidase. Deve-se levar em conta que as maiores médias de porcentagem dos sintomas ocorreram no genótipo SP903414 submetido ao tratamento 3 [Oxyfluorfen $\left(6 \mathrm{~mL} \mathrm{~L}^{-1}\right)$ ], com $80 \%$ da superficie foliar com sintoma (Tabela 2), evidenciando que a não utilização dos compostos antioxidantes (vitaminas $\mathrm{C} \mathrm{e}$ E) e precursores da rota metabólica (glutamato monossódico) fez aumentar os danos fotoxidativos causados nas folhas pela formação do oxigênio singleto. A adição das vitaminas $\mathrm{C}$ e E (-tocoferol), como ação antioxidante, teve como objetivo reverter os efeitos do oxigênio singleto produzido quando há interação da PROTO IX com oxigênio e luz. Já a adição do glutamato monossódico garantiu o suprimento por compostos precursores, sendo ele o principal precursor da sintese de porfirinas em plantas. Os tratamentos 2 e 8 , que superaram os demais no acúmulo de protoporfirina IX, foram os que apresentaram médias mais baixas de sintomas (Tabela 1), comprovando os resultados supracitados da ação dos antioxidantes e precursores. Outro fator relevante observado foi que no tratamento 8 os inibidores de PROTOX (oxyfluorfen e carfentrazone) não estão presentes, atuando somente o precursor (ácido levulênico) e antioxidantes (vitaminas C e E); portanto, são necessários maiores estudos, uma vez que pode se tornar uma alternativa interessante na produção de protoporfirina IX na terapia fotodinâmica, devido à não utilização dos inibidores anteriormente citados.

Uma característica comum aos inibidores da PROTOX é a expressiva degradação quando expostos a luz, mas não há informações sobre os comprimentos de onda que promovem sua inativação. A determinação desses comprimentos de onda pode permitir o desenvolvimento de procedimentos de fotólise dos compostos, reduzindo suas concentrações nas plantas, após a indução da produção da protoporfirina IX; contudo, é necessário que o comprimento de onda selecionado não induza a fluorescência do tetrapirrol. Também não se 
Tabela 1 - Médias das concentrações de porfirina $\left(\mu \mathrm{g} \mathrm{g}^{-1}\right)$ em oito genótipos de cana-de-açúcar submetidos a diferentes tratamentos. FCA/UNESP, Botucatu-SP, 2008

\begin{tabular}{|c|c|c|c|c|c|c|c|c|}
\hline \multirow{2}{*}{ Tratamento } & \multicolumn{8}{|c|}{ Genótipo } \\
\hline & PO933499 & RB806043 & RB470355 & PO830698 & SP701143 & PO901387 & SP903414 & PO894414 \\
\hline $1^{\frac{1 /}{}}$ & $11,75 \mathrm{Aa}^{2 /}$ & $11,25 \mathrm{Aa}$ & $13,50 \mathrm{Ba}$ & $11,75 \mathrm{Aa}$ & $10,50 \mathrm{ABa}$ & $14,50 \mathrm{Aa}$ & $12,50 \mathrm{Ba}$ & $10,00 \mathrm{Aa}$ \\
\hline 2 & $12,25 \mathrm{Ab}$ & $14,75 \mathrm{Ab}$ & $21,25 \mathrm{Aa}$ & $14,00 \mathrm{Ab}$ & $12,25 \mathrm{ABb}$ & $13,25 \mathrm{Ab}$ & $19,75 \mathrm{Aa}$ & $10,75 \mathrm{Ab}$ \\
\hline 3 & $12,00 \mathrm{Aab}$ & $14,25 \mathrm{Aa}$ & $14,50 \mathrm{Bab}$ & $14,50 \mathrm{Aab}$ & $12,75 \mathrm{ABab}$ & $12,75 \mathrm{Aab}$ & $9,50 \mathrm{Bb}$ & $11,50 \mathrm{Aab}$ \\
\hline 4 & $11,25 \mathrm{Aa}$ & $11,50 \mathrm{Aa}$ & $14,75 \mathrm{Ba}$ & $11,00 \mathrm{Aa}$ & $12,75 \mathrm{ABa}$ & $12,75 \mathrm{Aa}$ & $12,25 \mathrm{Ba}$ & $11,50 \mathrm{Aa}$ \\
\hline 5 & $14,75 \mathrm{Aa}$ & $10,25 \mathrm{Aab}$ & $13,50 \mathrm{Bab}$ & $10,00 \mathrm{Ab}$ & $10,50 \mathrm{ABab}$ & $11,00 \mathrm{Aab}$ & $10,25 \mathrm{Bab}$ & $12,25 \mathrm{Aab}$ \\
\hline 6 & $11,00 \mathrm{Aa}$ & $12,50 \mathrm{Aa}$ & $12,75 \mathrm{Ba}$ & $12,25 \mathrm{Aa}$ & $10,25 \mathrm{Ba}$ & $13,00 \mathrm{Aa}$ & $13,00 \mathrm{Ba}$ & $12,00 \mathrm{Aa}$ \\
\hline 7 & $12,00 \mathrm{Aa}$ & $13,75 \mathrm{Aa}$ & $12,25 \mathrm{Ba}$ & $12,25 \mathrm{Aa}$ & $12,25 \mathrm{ABa}$ & $14,25 \mathrm{Aa}$ & $11,50 \mathrm{Ba}$ & $14,25 \mathrm{Aa}$ \\
\hline 8 & $11,50 \mathrm{Aab}$ & $11,25 \mathrm{Aab}$ & $10,50 \mathrm{Bb}$ & $12,25 \mathrm{Aab}$ & $15,25 \mathrm{Aa}$ & $12,25 \mathrm{Aab}$ & $12,75 \mathrm{Bab}$ & $13,00 \mathrm{Aab}$ \\
\hline 9 & $11,50 \mathrm{Aa}$ & $12,00 \mathrm{Aa}$ & $12,00 \mathrm{Ba}$ & $11,25 \mathrm{Aa}$ & $10,00 \mathrm{Ba}$ & $11,00 \mathrm{Aa}$ & $10,75 \mathrm{Ba}$ & $11,50 \mathrm{Aa}$ \\
\hline F (tratamento) & \multicolumn{8}{|c|}{$3,676^{* *}$} \\
\hline F (genótipo) & \multicolumn{8}{|c|}{$7,010^{* *}$} \\
\hline $\mathrm{F}$ (trat $\mathrm{x}$ gen $)$ & \multicolumn{8}{|c|}{$2,612 * *$} \\
\hline CV $(\%)$ & \multicolumn{8}{|c|}{17,51} \\
\hline DMS (tratamento) & \multicolumn{8}{|c|}{4,81} \\
\hline DMS (genótipo) & \multicolumn{8}{|c|}{4,70} \\
\hline
\end{tabular}

1/ 1. oxyfluorfen + glutamato monossódico + vitaminas $\mathrm{C}$ e E; 2 . oxyfluorfen + glutamato monossódico + vitaminas $\mathrm{C}$ e $\mathrm{E}+$ ácido levulênico; 3. oxyfluorfen; 4. carfentrazone + glutamato monossódico + vitaminas C e E; 5. carfentrazone + glutamato monossódico + vitaminas $\mathrm{C}$ e $\mathrm{E}$ + ácido levulênico; 6. carfentrazone; 7. testemunha + vitaminas $\mathrm{C}$ e E; 8. testemunha + vitaminas $\mathrm{C}$ e $\mathrm{E}+$ ácido levulênico; 9. testemunha. $2 /$ Médias seguidas de mesma letra maiúscula, na coluna, e minúscula, na linha, não diferem estatisticamente entre si pelo teste de Tukey $(\mathrm{P}<0,05){ }^{* *}$ - significativo a $1 \%$ de probabilidade.

Tabela 2 - Escala percentual média de sintomas visuais (0-100\%) em folhas de cana-de-açúcar aos 2 DAA

\begin{tabular}{|c|c|c|c|c|c|c|c|c|}
\hline \multirow{2}{*}{ Tratamento } & \multicolumn{9}{|c|}{ Genótipo } \\
\cline { 2 - 10 } & PO933499 & RB806043 & RB470355 & PO830698 & SP701143 & PO901387 & SP903414 & PO894414 \\
\hline $1^{1 /}$ & 37,00 & 5,50 & 6,50 & 18,75 & 9,25 & 11,25 & 50,00 & 20,00 \\
\hline 2 & 11,50 & 2,50 & 30,00 & 9,00 & 20,00 & 10,00 & 47,50 & 34,00 \\
\hline 3 & 43,25 & 22,50 & 32,50 & 18,75 & 23,75 & 33,25 & 80,00 & 18,00 \\
\hline 4 & 2,50 & 0,25 & 11,50 & 6,25 & 1,25 & 0,75 & 4,00 & 12,75 \\
\hline 5 & 3,50 & 2,50 & 0,50 & 5,00 & 0,50 & 0,00 & 3,00 & 15,00 \\
\hline 6 & 3,25 & 1,50 & 0,25 & 2,25 & 1,25 & 0,25 & 3,25 & 4,00 \\
\hline 7 & 1,00 & 2,25 & 2,50 & 1,50 & 1,50 & 1,00 & 1,00 & 2,75 \\
\hline 8 & 3,75 & 1,50 & 0,00 & 4,00 & 1,00 & 1,50 & 1,00 & 2,00 \\
\hline 9 & 0,00 & 0,00 & 0,00 & 0,00 & 0,00 & 0,00 & 0,00 & 0,00 \\
\hline
\end{tabular}

1/ 1. oxyfluorfen + glutamato monossódico + vitaminas C e E; 2. oxyfluorfen + glutamato monossódico + vitaminas $\mathrm{C}$ e E + ácido levulênico; 3. oxyfluorfen; 4. carfentrazone + glutamato monossódico + vitaminas $\mathrm{C}$ e E; 5. carfentrazone + glutamato monossódico + vitaminas $\mathrm{C}$ e $\mathrm{E}+$ ácido levulênico; 6. carfentrazone; 7. testemunha + vitaminas $\mathrm{C}$ e $\mathrm{E}$; 8. testemunha + vitaminas $\mathrm{C}$ e $\mathrm{E}+$ ácido levulênico; 9. testemunha.

sabe se a supressão dos comprimentos que geram a degradação implicaria alteração da dose aplicada.

De modo geral, os aumentos na concentração de PROTO IX mostraram que em curto prazo foram detectadas diferenças significativas nas concentrações de protoporfirina IX nos genótipos RB470355, SP903414 e SP701143 submetidos aos tratamentos 2 e 8 , indicando que eles podem ser utilizados como fontes acumuladoras de protoporfirina IX. Novos ensaios com esses genótipos se fazem necessários, por eles se mostrarem promissores quanto ao objetivo proposto no trabalho. 


\section{LITERATURA CITADA}

BAKOS, R. M. et al. Terapêutica fotodinâmica com ácido delta-aminolevulínico em neoplasias queratinocíticas superficiais. An. Bras. Dermatol., v. 28, n. 2, p. 197-207, 2003.

CAPELLA, M. A. M.; CAPELLA, L. S. A Light multidrug resistance. photodynamic treatment of multidrug-resistant tumors. J. Biomed. Sci., v. 10, n. 10, p. 361-366, 2003.

DALTON, J. T. et al. Clinical pharmacokinetics of 5aminolevulinic acid in healthy volunteers and patients at high risk for recurrent bladder cancer. J. Pharmacol. Exper., v. 301, n. 2 , p. $507-512,2002$

DEMIDOVA, T. N.; HAMBLIN, M. R. Photodynamic therapy targeted to pathogens. Int. J. Immunopathol. Pharmacol., v. 17, n. 3, p. 245-254, 2004.

DEMIDOVA, T. N.; HAMBLIN, M. R. Effect of cellphotosensitizer binding and cell density on microbial photoinactivation. Antimicrob. Agents Chemother., v. 49, n. 6, p. 2329-2335, 2005.

DODGE, A D. Photosynthesis. In: KIKWOOD, R. C. Target sites for herbicide action. Glasgow: University of Stranthclyde, 1992. p. 1-27.

GAD, F. et al. Effects of growth phase and extracellular slime on photodynamic inactivation of gram-positive pathogenic bacteria. Antimicrob. Agents Chemother., v. 48, n. 6 , p. $2173-2178,2004$

HAMBLIN, M. R.; HASAN, T. Photodynamic therapy: a new antimicrobial approach to infectious disease?

Photochem. Photobiol. Sci., v. 3, n. 5, p. 436-450, 2004.
HESS, F. D. Herbicide effects on plant structure, physiology and biochemistry. In: ALTMAN, J. Pesticide interactions in crop production beneficial and deleterious effects London: CRC Press, 1993. p. 579.

LAMBRECHTS, S. A. G.; AALDERS, M. C. G.; MARLE, J. V. Mechanistic study of the photodynamic inactivation of Candida albicans by a cationic porphyrin. Antimicrob. Agents Chemother., v. 49, n. 5, p. 2026-2034, 2005.

MENEZES, P. F. C. et al. Dark cytotoxicity of the photoproducts of the photobleaching induced by a laser. Laser Physics, v. 15, n. 3, p. 1-8, 2005.

NELSON, D. L.; COX, M. M. Principles of biochemistry 3.ed. New York: Worth Publishers, 2000. 1152 p.

PORNPROM, T. et al. Characterization of oxyfluorfen tolerance in selected soybean cell line. Pest. Biochem. Physiol., v. 50, n. 2, p. 107-114, 1994.

SHERMAN, D.T. et al. Physiological basis for differential sensitivities of plant species to protoporphyrinogen oxidaseinhibiting herbicides. Plant Physiol., v. 97, n. 1, p. 280-287, 1991.

WATANABE, N. et al. Dual targeting of spinach protoporphyrinogen oxidase II to mitochondria and chloroplasts by alternative use of in-frame initiation codons. J. Biol. Chem., v. 276, n. 23, p. 20447-20481, 2001.

XIAO, Z. et al. Biodistribution of photofrin II and aminolevulinic acid-induced protoporphyrin IX in normal rat bladder tumor models: implications for photodynamic therapy. Photochem. Photobiol., v. 67, n. 5, p. 573-83, 1998. 